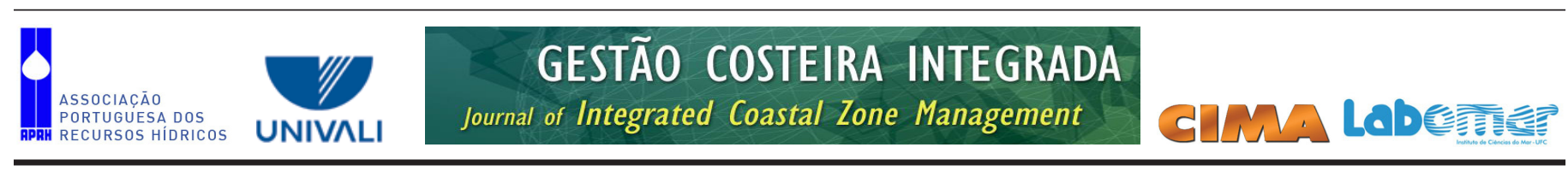

http://www.aprh.pt/rgci/pdf/rgci-384_Vecozzi.pdf | DOI:10.5894/rgci384

\title{
0 licenciamento ambiental nas operações portuárias: estudo de caso aplicado aos operadores do terminal Porto Novo no porto organizado do Rio Grande, RS, Brasil *
}

\section{Environmental licensing in port operations: a case study applied to operators of Porto Novo terminal in organized port of Rio Grande, RS, Brazil}

\author{
Thaís Antolini Veçozzi ${ }^{\circledR,}$, , Alexandre Caldeirão Carvalho $^{1}$
}

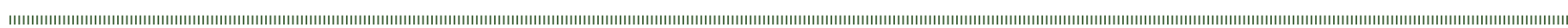

\section{RESUMO}

O desempenho ambiental, que pode mostrar-se de grande relevância na competitividade das empresas é resultado, dentre outros fatores, de exigências legais como o licenciamento ambiental. Como um instrumento de gestáo, o licenciamento é exigido legalmente para empreendimentos utilizadores de recursos naturais considerados potencial ou efetivamente poluidores e, em razão disso, é nítida a necessidade de licença ambiental para operadores portuários. Contudo, no Terminal Porto Novo do Porto Organizado do Rio Grande esta questão ainda é controvérsia e não esclarecida legalmente. As discussóes sobre o licenciamento ambiental presentes neste estudo refletem, em parte, o estado da arte da gestão ambiental portuária e demostram o assunto com diferentes pontos de vista que constitui o licenciamento ambiental neste terminal portuário. Sendo assim, expóe a discussão sobre os vários fatores contribuintes para que esta realidade permaneça estática, entre eles o fato dos operadores concluírem que suas atividades estão cobertas pela Licença de Operação do Porto Organizado, as divergências existentes com relação à competência dos órgãos ambientais e a deficiência na fiscalização por parte da Autoridade Portuária. A metodologia utilizada foi a de estudo de caso, aplicada ao Terminal Porto Novo do Porto Organizado do Rio Grande. Para tal, primeiramente foram esclarecidos alguns conceitos a respeito de gestão ambiental, das atividades realizadas por operadores portuários, como se organiza e a quem compete a administração portuária e o licenciamento ambiental. Após isso, foram aplicados questionários aos operadores portuários do Terminal Porto Novo e foi realizada uma entrevista com a diretora da Divisáo de Meio Ambiente, Saúde e Segurança da Superintendência do Porto Organizado do Rio Grande. Com isso, concluiu-se que é nítida a necessidade de licença ambiental para operadores portuários, sendo o mais apropriado delegar esta responsabilidade ao órgão ambiental estadual, devido aos impactos ambientais das organizaçóes e empresas instaladas neste Terminal poderem ultrapassar os limites territoriais de mais de um município, ou seja, o do Rio Grande e de São José do Norte. Mesmo havendo contestações, uma indicação ao atendimento desta problemática é o licenciamento único do Porto Organizado e a configuração da Autoridade Portuária como órgão licenciador das atividades exercidas dentro de sua área. Ademais, outra proposta pautável seria a do autolicenciamento, ideia bastante discutida e apoiada nas esferas federais. Distante do que é entendido pelos operadores portuários, suas atividades não estáo cobertas pela Licença de Operação do Porto Organizado, pois as condicionantes desta LO não fazem menção alguma às atividades destes atores. Uma das consideraçôes mais importantes sobre a questáo tratada é o fato do conhecimento dos órgãos ambientais ainda não estar claro sobre o limite que separa as responsabilidades entre as Autoridades Portuárias e os operadores portuários.

Palavras-chave: Licença Ambiental, Atividades Portuárias, Competência institucional.

@ - Corresponding author

1 - Universidade Federal do Rio Grande, Instituto de Oceanografia (IO), Laboratório de Gerenciamento Costeiro, Rio Grande, RS, Brasil. E-mails: Veçozzi -thais_antolini@hotmail.com; Carvalho-acaldeirao@gmail.com 


\section{ABSTRACT}

The environmental performance, which may prove very important in the competitiveness of enterprises is the result, among other factors, of the legal requirements and environmental licensing. As a management tool, the license is legally required for users of natural resources endeavors considered or potentially polluting and, for this reason, it is clear a need for an environmental permit for port operators. However, even being a legal obligation, in the case of Porto Novo Terminal of Organized Port of Rio Grande, the process of environmental licensing of its port operators is still unclear. The set of discussions presented in this study demonstrates the factors that contribute to the current reality of Terminal Porto Novo regarding the environmental licensing of its operators, reflecting in part the state of the art port environmental management and highlighting the issue with different points of view as that constitutes. Thus, exposes the discussion about the various contributors of this reality, including the fact that the operators conclude that their activities are covered by the operating license of the Organized Port, the divergences in relation to the competencies of the bodies environmental and deficiency in the oversight by the Port Authority. The methodology used was the case study, applied to Terminal Porto Novo Organized Port of Rio Grande. For such, primarily some concepts were clarified regarding environmental management of activities undertaken by port operators, how is organized and who is responsible for port management and environmental licensing. After this, questionnaires were administered to port operators Terminal Porto Novo and an interview was conducted with the director of the Division of Environmental Health and Safety of the Organized Port of Rio Grande Organized. Through the systematization of information collected, port operators, their activities and the environmental management of the Terminal were characterized. Thus, it was concluded that there is clear need for environmental permit for port operators. Due to the high degree of polluting activities and natural features of the hydrodynamics of the Patos Lagoon estuary, the environmental impacts generated by port operators Terminal Porto Novo can reach two cities, Rio Grande and São José do Norte. Thus, according to Brazilian law, the competence of the environmental licensing of these developments should not be delegated to the municipal environmental agency. Moreover, the municipal government needs major mobilization in relation to the training of professionals responsible for the process of issuing environmental permits and inspection of licensed activities. In addition, jurisdiction over the licensing of operations developed in the federal area with high pollution potential should be minimally assigned to the state environmental agency. The activities of the port operators, far from what is understood by these actors are not covered by the Operating License Organized Port. In its period of validity, which is eight years, companies that operate in Terminal can be changed because their contracts are independent of this environmental permit. Furthermore, the constraints of this $L O$ make no mention to the activities of the operators of any port terminals. According to the Brazilian environmental legislation, environmental licensing of activities exercised in the Organized Port of Rio Grande should be left to the federal environmental agency, because of its domain area is the Union However, IBAMA delegates the licensing of port operations private terminals to the state agency. Based on this premise, the licensing of operators installed within Terminal Porto Novo should keep this line, the most appropriate to delegate this responsibility to the state environmental agency. The issue is that knowledge of environmental agencies, whether federal, state or municipal are unclear about the boundary separating the responsibilities between the port authorities and port operators. This situation prevents the full attendance of the issues assigned to them by the environmental conditions on the basis of the licenses. An indication paring address this problem is unique licensing Organized Port and configuration of the Port Authority as the licensing authority of the activities performed within their area. However, delegate this task to the Port of Rio Grande could be considered a mistake, due to the fact of SUPRG owning interest in moving goods made by operators. Another proposal would be "self-licensing", idea widely discussed and supported by the federal, mainly in the Special Secretariat of Ports, regarding the environmental licensing in Brazil port.

Keywords: Environmental Permit, Port Activities, Institutional Competence.

\section{INTRODUÇÃO}

Os avanços no atendimento às novas exigências ambientais no âmbito das atividades portuárias são resultado, dentre outros fatores, das exigências apresentadas na legislação vigente. Mas este progresso, para ser percebido e efetivamente consolidado nos portos depende da participação e adequação dos operadores portuários que desenvolvem suas atividades no interior das instalaçóes portuárias. Neste contexto o licenciamento ambiental é o principal instrumento da Política Nacional de Meio Ambiente - PNMA, estabelecida pela Lei Federal no 6.938, de 31 de agosto de 1981.

No processo de licenciamento ambiental o órgão ambiental competente autoriza empreendedores a desenvolver atividades consideradas potencial ou efetivamente poluidoras, garantindo que estas estejam em consonância com a legislação ambiental, sem prejuízo à qualidade de vida das populaçôes humanas e dos recursos naturais.

Contudo, mesmo sendo uma obrigação legal, os processos de licenciamento ambiental dos operadores portuários que desenvolvem suas atividades no interior das dependências administradas diretamente pela Autoridade Portuária Superintendência do Porto do Rio Grande (SUPRG) ainda não está esclarecido. Vários operadores ainda não possuem Licença de Operação e aqueles que a possuem a tramitaram junto ao órgão ambiental municipal, o que gera conflitos no âmbito das competências, uma vez que o Porto Organizado como um todo possui Licença de Operaçáo expedida pelo órgão nacional (IBAMA) e os terminais privativos possuem licenças expedidas pelo órgão estadual (FEPAM).

A priori algumas causas dessa confusa realidade são a alegação de que as atividades dos operadores portuários estariam cobertas pela LO do Porto Organizado, pois estes desenvolvem suas atividades no interior de um terminal licenciado, as divergências existentes com relação à competência dos órgãos ambientais (federal, estadual e municipal) e a deficiência na fiscalizaçáo exercida pela Autoridade Portuária. Sendo assim, o presente trabalho se propóe discutir o licenciamento ambiental dos operadores portuários instalados no Terminal Porto Novo do Porto Organizado do Rio Grande. 
O presente trabalho foi dividido em seçóes, a primeira constitui-se de uma apresentação geral do estudo, a Seção 2 demostra como se desenvolveu a análise, na terceira realiza-se uma revisão bibliográfica sobre o setor portuário, licenciamento ambiental e competência dos órgãos ambientais, na Seção 4 o Porto do Rio Grande é caracterizado e é apresentado o estado da arte de sua gestão ambiental, na Seçáo 5 são exibidos os aspectos da pesquisa de campo, os operadores portuários são caracterizados e a abrangência de seus impactos ambientais potenciais é descrita e na Seção 6 é feita a discussão final sobre a competência do licenciamento dos operadores portuários para o adequado atendimento da problemática de pesquisa.

\section{METODOLOGIA}

Considerando as atividades desenvolvidas e os assuntos discutidos, este trabalho consiste em um estudo de caso. Segundo Bruyne, Herman e Schoutheete (1977), "o estudo de caso justifica sua importância por reunir informaçóes numerosas e detalhadas com vista em apreender a totalidade de uma situação. A riqueza das informaçóes detalhadas auxilia num maior conhecimento e numa possível resolução de problemas relacionados ao assunto estudado". Logo, adequa-se ao esclarecimento da discussão proposta.

Como uma abordagem inicial para compreensão de algumas questôes, a revisão bibliográfica abordou temas como gestão ambiental e conceitos enunciados pela Lei Federal $n^{\circ}$ 8.630, de 25 de fevereiro de 1993. Além disso, foram feitos esclarecimentos a respeito da competência das Autoridades Portuárias e dos órgãos ambientais. A legislação que dispóe sobre o licenciamento ambiental e estabelece suas diretrizes e obrigaçóes, no âmbito federal, estadual e municipal mostrouse imprescindível para a realização da análise.

Com a definição da área de estudo limitada ao Terminal Porto Novo do Porto do Rio Grande, seus operadores portuários foram identificados através de saídas de campo auxiliadas pela Divisão de Meio Ambiente, Saúde e Segurança - DMASS, da Superintendência do Porto do Rio Grande - SUPRG. Na caracterização desses operadores e de suas atividades, aplicou-se um questionário (Tabela 5) a cada uma das empresas. Os dados coletados foram sistematizados e estão apresentados na Seção 5 deste trabalho.

Estando o licenciamento ambiental dos operadores portuários disposto em um âmbito de maior escala, que é a gestão ambiental do Porto Organizado do Rio Grande, esta foi caracterizada com auxílio de uma entrevista com a diretora da DMASS, por meio da qual foram coletados os dados utilizados na Seção 4.

\section{REFERENCIAL TEÓRICO}

Localizados próximos a rios, lagos ou oceanos, os portos são instalaçóes adequadas à movimentação e armazenamento das mais diversas mercadorias por meio do modal aquaviário. E representam um papel essencial para a economia do país, uma vez que por eles passam 95\% do comércio exterior brasileiro, de acordo com dados da Agência Nacional de Transportes Aquaviários - ANTAQ ${ }^{1}$.

1 - www.antaq.gov.br/Portal/GestaoPortuaria/Index.asp
Alguns portos, como o do Rio Grande, são divididos em Terminais de Uso Privativo - TUP's e terminais de uso público arrendados à empresas privadas. As organizaçóes e empresas que desenvolvem atividades nestas áreas são denominadas "Operadores Portuários" e realizam atividades semelhantes à dos portos, pois movimentam mercadorias próprias ou de terceiros. As taxas desses arrendamentos são cobradas pela Autoridade Portuária de acordo com o volume de carga movimentada.

A regulação do setor portuário brasileiro é feita por dois órgãos federais, a Agência Nacional de Transportes Aquaviários - ANTAQ, criada em 2001, e a Secretaria Especial de Portos da Presidência da República. A primeira vinculada ao Ministério dos Transportes exerce uma função reguladora e a segunda, ligada diretamente à Presidência da República e com status de ministério se preocupa da política portuária brasileira, atuando como um órgáo de fomento.

A administração direta dos portos é responsabilidade das Autoridades Portuárias, dispostas ao longo do território brasileiro e divididas entre Companhias Docas, Superintendências Estaduais e Municipais e entidades de administração privada (Porto de Imbituba - SC). A organização das entidades e autoridades portuárias encontrase disposta no Figura 1, a seguir. Dentre outras competências, é encargo das Autoridades Portuárias "fiscalizar as operaçôes portuárias, zelando para que os serviços se realizem com regularidade, eficiência, segurança e respeito ao meio ambiente", conforme a Lei Federal no 8.630/93.

O conjunto seguinte de conceitos foi retirado da Lei de Modernização dos Portos ( $\mathrm{n}^{\circ}$ 8.630/93) e pela tamanha relevância de sua compreensão, apresenta-se destacado na Tabela 1, a seguir.

A gestão ambiental engloba muitos dos assuntos abordados neste texto. Em seu âmbito, o licenciamento ambiental é tratado como um instrumento de gestấo. Portanto, gestão ambiental é aqui entendida como "a diretriz e a atividade administrativa e operacional, tal como planejamento, direção, controle, alocação de recursos e outras realizadas com o objetivo de obter efeitos positivos sobre o meio ambiente, quer reduzindo ou eliminando os danos ou problemas causados pelas açóes humanas, quer evitando que eles surjam" (Barbieri, 2004).

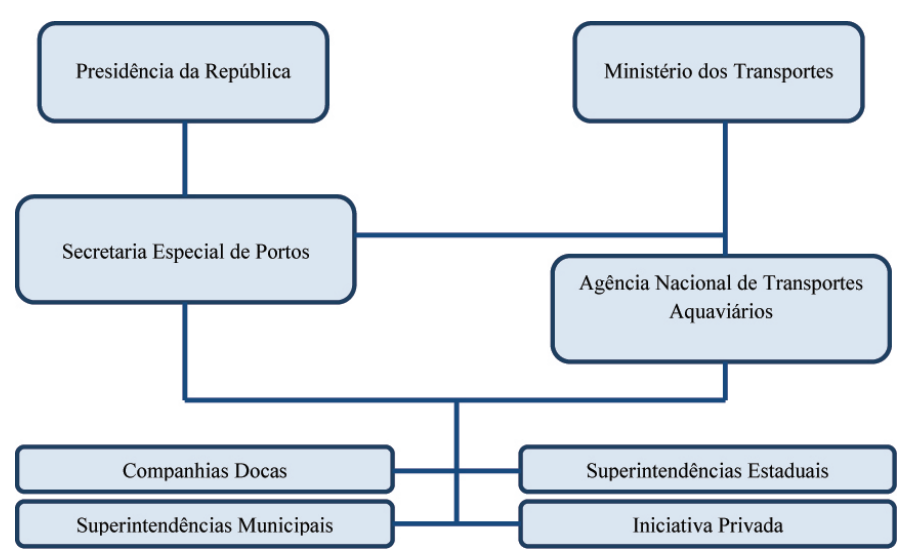

Figura 1. Hierarquização das Entidades e Autoridades Portuárias. Figure 1. Terminal Porto Novo Organized Port of Rio Grande. 
Tabela 1. Conceitos publicados pela Lei de Modernização dos Portos (Lei 8.630 de 25 de fevereiro de 1993).

Table 1. Concepts published by the Port Modernization Law (Lei 8.630 de 25 de fevereiro de 1993).

\begin{tabular}{ll}
\hline Porto Organizado: & $\begin{array}{l}\text { Aquele construído e aparelhado para atender às necessidades da navegação, } \\
\text { da movimentação de passageiros ou da movimentação e armazenagem de } \\
\text { mercadorias, concedido ou explorado pela União, cujo tráfego e operaçóes } \\
\text { portuárias estejam sob a jurisdição de uma autoridade portuária; }\end{array}$ \\
\hline Operaçáo Portuária: & $\begin{array}{l}\text { A de movimentação de passageiros ou a de movimentação ou armazenagem } \\
\text { de mercadorias, destinados ou provenientes de transporte aquaviário, realizada } \\
\text { no porto organizado por operadores portuários; }\end{array}$ \\
\hline Operador portuário: & $\begin{array}{l}\text { A pessoa jurídica pré-qualificada para a execução de operação portuária na } \\
\text { área do porto organizado. }\end{array}$ \\
\hline
\end{tabular}

Por ser um conjunto de grande extensão, envolvendo instrumentos legais e voluntários, de maneira interdisciplinar, na gestão ambiental não há a demarcação de uma fronteira para sua atuação. $\mathrm{O}$ licenciamento ambiental, por tratar-se de um procedimento de controle da degradação ambiental, integra este conjunto dinâmico e de grande relevância socioambiental.

A legislação que dispóe sobre o licenciamento ambiental e estabelece suas diretrizes, obrigaçóes e competências também merece destaque. O licenciamento ambiental é um instrumento da Política Nacional do Meio Ambiente, instituído em 1981 pela Lei Federal no 6.938 e "é o procedimento administrativo pelo qual o órgáo ambiental competente licencia a localização, instalação, ampliação e a operaçáo de empreendimentos e atividades utilizadoras de recursos ambientais, consideradas efetiva ou potencialmente poluidoras ou daquelas que, sob qualquer forma, possam causar degradação ambiental", de acordo com a Resolução CONAMA 237/93. Conforme esta Resolução, as licenças expedidas pelos órgãos ambientais competentes são as seguintes:

I - Licença Prévia (LP) - na fase preliminar, de planejamento do empreendimento ou atividade;

II- Licença de Instalação (LI) - autorizando o início da implantação do empreendimento ou atividade, de acordo com as condiçóes e restriçóes da LP;

III - Licença de Operação (LO) - autorizando, após as verificações necessárias, o início do empreendimento ou atividade.

Assim, a Resolução 237/93 estabelece, em seu Artigo 4º, que compete ao Instituto Brasileiro do Meio Ambiente e dos Recursos Naturais Renováveis - IBAMA, o licenciamento ambiental de empreendimentos e atividades com significativo impacto ambiental de âmbito nacional ou regional, e, em seu Artigo $5^{\circ}$, a competência dos órgãos estaduais, que envolve as atividades localizadas ou desenvolvidas em mais de um Município ou em unidades de conservação de domínio estadual ou do Distrito Federal; as localizadas ou desenvolvidas nas florestas e demais formas de vegetação natural de preservação; as cujos impactos ambientais diretos ultrapassem os limites territoriais de um ou mais Municípios, e as delegadas pela Uniáo aos Estados ou ao Distrito Federal, por instrumento legal ou convênio (Tabela 2).
Quanto à competência dos órgãos ambientais municipais, cabe a eles o licenciamento ambiental dos empreendimentos e atividades consideradas como de impacto local, bem como aqueles que lhe forem delegados pelo Estado por instrumento legal ou convênio. A lista com a tipologia dos empreendimentos e atividades consideradas de impacto local no Município do Rio Grande, e que devem ser licenciadas pela Secretaria Municipal de Meio Ambiente - SMMA encontra-se no anexo único da Resolução CONDEMA 001/11. A SMMA também é responsável pela fiscalização das atividades por ela licenciadas, segundo a Lei Municipal 6.365/07, que dispóe sobre o licenciamento ambiental neste Município.

\section{CARACTERIZAÇÁO DO PORTO ORGANIZADO DE RIO GRANDE}

O Porto do Rio Grande localiza-se geograficamente no Estuário da Lagoa dos Patos em área pertencente à União. As Zonas Portuárias estão divididas em Terminal Porto Velho, Terminal Porto Novo, Superporto e São José do Norte, algumas das quais fazem limite com as áreas urbanas dos municípios do Rio Grande e São José do Norte. Estas áreas são administradas pelo Estado do Rio Grande do Sul através da Superintendência do Porto do Rio Grande - SUPRG. De acordo com Demore (2001), toda a área entorno de onde se desenvolvem as operaçôes do Terminal de Rio Grande, encontra-se situada no interior do estuário e na plataforma continental adjacente, em um ambiente de características múltiplas e facilmente impactável.

A consideração dos aspectos referentes à hidrodinâmica do Estuário da Lagoa dos Patos é de singular importância para a compreensão da magnitude dos impactos ambientais deste Porto. Como afirma Möller et al. (1991), por esta laguna estar situada numa planície, ela recebe a açáo direta dos ventos, que são particularmente fortes durante outono e inverno. De acordo com a ideia de Delaney (1965) e DHN (1974), é influenciada por um regime de ventos predominantemente NE-SW, os do quadrante NE (velocidade média 3,6-5,1 m $\mathrm{s}^{-1}$ ) ocorrem durante $22 \%$ do ano e os do quadrante SW (velocidade média 5,7-8,2 $\mathrm{m} \mathrm{s}^{-1}$ ) durante 12\%.

Eles ventos controlam decisivamente a circulaçáo e os níveis de água, embora a descarga fluvial possa, também, gerar gradientes de pressão sazonais, com elevados níveis 
Tabela 2. Competência do Licenciamento Ambiental em âmbito Federal, Estadual e Municipal (segundo a resolução CONAMA no 237, de 19 de dezembro de 1997).

Table 2. Competency of Environmental Licensing in the Federal, State and Municipal levels (accordingly to CONAMA Resolution No. 237, of December 19, 1997).

\section{Compete à Uniáo o Licenciamento Ambiental de empreendimentos:}

- Localizadas ou desenvolvidas conjuntamente no Brasil e em país limítrofe, no mar territorial, na plataforma continental, na zona econômica exclusiva, em terras indígenas ou em unidades de conservaçáo do domínio da Uniáo;

- Localizadas ou desenvolvidas em dois ou mais Estados;

- Cujos impactos ambientais diretos ultrapassem os limites territoriais do País ou de um ou mais Estados;

- Destinados a pesquisar, lavrar, produzir, beneficiar, transportar, armazenar e dispor material radioativo, em qualquer estágio, ou que utilizem energia nuclear em qualquer de suas formas e aplicaçóes, mediante parecer da Comissáo Nacional de Energia Nuclear - CENEN;

- Bases ou empreendimentos militares, quando couber, observada a legislação específica.

\section{Compete aos Estados o Licenciamento Ambiental de empreendimentos:}

- Localizados ou desenvolvidos em mais de um Município ou em unidades de conservação de domínio estadual ou do Distrito Federal;

- Localizados ou desenvolvidos nas florestas e demais formas de vegetação natural de preservação permanente relacionadas no Artigo $2^{\circ}$ da Lei no 4.771, de 15 de setembro de 1965, e em todas as que assim forem consideradas por normas federais, estaduais ou municipais;

- Cujos impactos ambientais diretos ultrapassem os limites territoriais de um ou mais Municípios;

- Delegados pela União aos Estados ou ao Distrito Federal, por instrumento legal ou convênio.

\section{Compete aos Municípios o Licenciamento Ambiental de empreendimentos:}

- Consideradas como de impacto local, bem como aquelas que lhe forem delegadas pelo Estado por instrumento legal ou convênio.

de água após o início de um período chuvoso (Seeliger et al. 1998). A descarga de água doce varia consideravelmente entre veráo/outono e inverno/primavera (6 a $5.300 \mathrm{~m}^{3} \mathrm{~s}-1$ da bacia de Camaquá e 41 a $25.000 \mathrm{~m}^{3} \mathrm{~s}-1$ da bacia do Guaíba). Especialmente durante os anos sob influência do El Niño, a descarga continental excede bastante os valores médios (Herz, 1977). Seguindo DNPVN (1941), no canal de acesso, as velocidades de fluxo de saída de água podem alcançar 1,7-1,9 $\mathrm{m} \mathrm{s}^{-1}$ após prolongados períodos de chuvas fortes.

Em 2012, o Porto do Rio Grande movimentou 27.744.975 toneladas de carga. As principais mercadorias movimentadas são carga geral, granel sólido, granel líquido, roll-on/roll-off, fertilizantes e contêineres. As atividades comerciais exercidas na área do Porto Organizado abrangem venda e processamento de pescado, construção e reparo naval, indústrias, movimentação e armazenamento de cargas. Os operadores portuários instalados no Terminal Porto Novo estão apresentados na Tabela 3:
Tabela 3. Operadores Portuários do Terminal Porto Novo. Table 3. Porto Novo terminal operators

Operadores Portuários do Terminal Porto Novo Agência Marítima Orion Ltda.

Sagres Agenciamentos Marítimos Ltda.

Sampayo Nickhorn S/A

Cisa Trading GSA

Guanabara Veículos Ltda.

Companhia Estadual de Silos e Armazéns - CESA

Vanzin Serviços Aduaneiros

Serra Morena 
A gestão ambiental do Terminal Porto Novo foi caracterizada por meio de uma entrevista semiestruturada (Tabela 4) com a diretora da Divisão de Meio Ambiente, Saúde e Segurança - DMASS, onde foram coletados os dados utilizados para a presente análise. A DMASS é a divisão responsável pela gestão ambiental em todo o Porto Organizado. Os instrumentos utilizados no auxílio da gestão ambiental por este setor são o Plano de Desenvolvimento e Zoneamento (PDZ), Plano de Emergência Individual (PEI), Monitoramento Ambiental, Plano de Auxílio Mútuo (PAM), Programa de Prevenção sobre Riscos Ambientais (PPRA), Estudo de Impacto Ambiental (EIA), Plano de Gerenciamento de Resíduos Sólidos (PGRS) e Licença de Operação expedida pelo IBAMA. Como uma ferramenta institucional, a DMASS ainda possui um Conselho de Gestão Ambiental, utilizado para escutar e transmitir informaçóes e orientaçóes aos operadores portuários de todo o Porto Organizado.

\section{CARACTERIZAÇÁO DOS OPERADORES PORTUÁRIOS E DASS ATIVIDADES QUE EXERCEM NO PORTO NOVO DO RIO GRANDE}

Após uma coleta inicial de dados, buscou-se caracterizar os operadores e suas atividades. Com essa finalidade, aplicou-se um questionário a todos estes atores (Tabela 5). As questóes

Tabela 4. Entrevista semiestruturada aplicada à diretora da DMASS, do Porto de Rio Grande.

Table 4. Subjects pre-set semi-structured interviews applied to the director of DMASS, the Port of Rio Grande.

\begin{tabular}{l}
\multicolumn{1}{c}{$\begin{array}{c}\text { Assuntos pré-estabelecidos da entrevista aplicada à } \\
\text { DMASS }\end{array}$} \\
\hline Núcleo Ambiental \\
\hline Plano de Desenvolvimento e Zoneamento \\
\hline Agenda Ambiental Institucional \\
\hline Plano de Emergência Individual - PEI \\
\hline Monitoramento Ambiental \\
\hline Serviço Especializado em Segurança e Saúde do Trabalhador \\
Portuário - SESSTP \\
\hline Gestão de Cargas Perigosas (IMO) \\
\hline Plano de Controle de Emergência - PCE e Plano de Ajuda \\
Mútua - PAM \\
\hline Programa de Prevenção de Riscos Ambientais - PPRA \\
\hline Gerenciamento de Resíduos Sólidos \\
\hline Auditoria \\
\hline Licenciamento Ambiental \\
\hline Passivos Ambientais \\
\hline Dragagem \\
\hline
\end{tabular}

propostas abrangiam a identificação do empreendimento, dados operacionais, tipologia das cargas movimentadas, documentação de meio ambiente, e manutenção de equipamentos.

A sistematização das informações coletadas (Tabela 6) demostrou o quanto estes atores diferem uns dos outros. Das oito empresas que estão instaladas no Porto Novo do Rio Grande, cinco ocupam armazéns e três possuem somente escritório. Duas dessas oito empresas realizam movimentação de contêineres, carga roll-on/roll-off e Projetos (cargas variadas) - Agência Marítima Orion e Sagres Agenciamentos Marítimos, uma movimenta contêineres e carga roll-on/ roll-off - Sampayo Nickhorn, uma realiza movimentação de contêineres e granéis sólidos e líquidos - Serra Morena,

Tabela 5. Questionário aplicado aos operadores portuários do Terminal Porto Novo do Rio Grande.

Table 5. Questionnaire applied to port operators Terminal Porto Novo Rio Grande.

\section{Operadores Portuários - Terminal Porto Novo de Rio Grande}

1 - Identificaçáo da empresa

Nome:

Responsável:

Telefone:

E-mail:

Entrevistado:

\section{2 - Dados operacionais}

Área de abrangência (física/operacional):

\section{3 - Carga movimentada (tipologia)}

Granel (sólido/líquido):

Contêineres:

Roll-on/roll-off:

Carga viva:

Passageiros:

4 - Documentação

PGRS:

PEI:

Licença Ambiental:

Certificação ambiental voluntária:

MTRs:

\section{5 - Manutençáo}

Equipamentos:

Local: 
Tabela 6. Caracterização dos operadores portuários do Porto Novo do Rio Grande.

Table 6. Characterization of Porto Novo Rio Grande port operators.

\begin{tabular}{|c|c|c|c|c|}
\hline Nome da empresa & $\begin{array}{c}\text { Área de } \\
\text { abrangência }\end{array}$ & $\begin{array}{l}\text { Tipologia de } \\
\text { carga }\end{array}$ & Documentaçâo & $\begin{array}{l}\text { Manutençáo de } \\
\text { equipamentos }\end{array}$ \\
\hline $\begin{array}{l}\text { Agência Marítima } \\
\text { Orion Ltda. }\end{array}$ & $\begin{array}{l}\text { Contêiner ao lado } \\
\text { do armazém B2 }\end{array}$ & $\begin{array}{l}\text { Contêineres, } \\
\text { Roll-on/roll-off e } \\
\text { *Projetos }\end{array}$ & $\begin{array}{l}\text { PGRS em } \\
\text { atualização, PEI do } \\
\text { Porto }\end{array}$ & $\begin{array}{l}\text { Nos locais onde se } \\
\text { encontram. Serviço } \\
\text { terceirizado }\end{array}$ \\
\hline $\begin{array}{l}\text { Sagres } \\
\text { Agenciamentos } \\
\text { Marítimos Ltda. }\end{array}$ & $\begin{array}{l}\text { Partes dos } \\
\text { armazéns C1, C2 } \\
\text { e C4 e a totalidade } \\
\text { dos B1, B2, B3, } \\
\text { B4 e B5 }\end{array}$ & $\begin{array}{l}\text { Contêineres, } \\
\text { Roll-on/roll-off e } \\
\text { Projetos }\end{array}$ & $\begin{array}{l}\text { PGRS, PEI do } \\
\text { Porto, Licença } \\
\text { Ambiental } \\
\text { (SMMA) e MTR }\end{array}$ & $\begin{array}{l}\text { Oficina no } \\
\text { armazém B1 }\end{array}$ \\
\hline $\begin{array}{l}\text { Sampayo Nickhorn } \\
\text { S/A }\end{array}$ & $\begin{array}{l}\text { Armazéns C5, A6, } \\
\text { A7 e A7/8. }\end{array}$ & $\begin{array}{l}\text { Contêineres e } \\
\text { Roll-on/roll-off }\end{array}$ & PGRS & $\begin{array}{l}\text { Realizada } \\
\text { externamente ao } \\
\text { Porto }\end{array}$ \\
\hline Cisa Trading GSA & $\begin{array}{l}\text { Escritório entre os } \\
\text { armazéns B4 e B5 }\end{array}$ & Roll-on/roll-off & PGRS & $\begin{array}{l}\text { Não possuem } \\
\text { equipamentos }\end{array}$ \\
\hline $\begin{array}{l}\text { Guanabara Veículos } \\
\text { Ltda. }\end{array}$ & $\begin{array}{l}\text { Armazéns C6, B6 } \\
\text { e a área entre estes } \\
\text { armazéns }\end{array}$ & Roll-on/roll-off & $\begin{array}{l}\text { PGRS e ** Licença } \\
\text { Provisória e MTR }\end{array}$ & $\begin{array}{l}\text { Oficinas nos } \\
\text { armazéns C6 e B6 }\end{array}$ \\
\hline $\begin{array}{l}\text { Companhia } \\
\text { Estadual de Silos e } \\
\text { Armazéns - CESA }\end{array}$ & $\begin{array}{l}\text { Silos e esteira de } \\
\text { carregamento }\end{array}$ & Graneis sólidos & $\begin{array}{l}\text { PGRS, PEI e } \\
\text { Protocolo de } \\
\text { Licença (Fepam) }\end{array}$ & $\begin{array}{l}\text { Oficina junto aos } \\
\text { silos }\end{array}$ \\
\hline $\begin{array}{l}\text { Vanzin Serviços } \\
\text { Aduaneiros }\end{array}$ & $\begin{array}{l}\text { Contêiner em } \\
\text { frente ao armazém } \\
\text { B1 }\end{array}$ & Graneis sólidos & - & $\begin{array}{l}\text { Nos locais onde se } \\
\text { encontram }\end{array}$ \\
\hline Serra Morena & $\begin{array}{l}\text { Parte sul do } \\
\text { Armazém C1 }\end{array}$ & $\begin{array}{l}\text { Contêineres, } \\
\text { Graneis sólidos e } \\
\text { líquidos }\end{array}$ & PGRS, PEI, & Emergencial \\
\hline
\end{tabular}

* Cargas variadas que são movimentadas esporadicamente.

** $\mathrm{O}$ vocabulário presente nesta tabela foi o utilizado pelos entrevistados.

uma somente carga roll-on/roll-off - Sisa Trading, e ainda há movimentaçấo de granéis sólidos por parte da CESA e da Vanzin Serviços Aduaneiros. A empresa Guanabara Veículos não efetua operação portuária diretamente, somente realiza reparos em veículos para a General Motors Ltda..

Quanto à documentação ambiental, seis operadores portuários possuem PGRS (Plano de Gerenciamento de Resíduos Sólidos); dois estão licenciados ambientalmente, mas apenas um apresenta LO expedida pela Secretaria Municipal de Meio Ambiente e um declarou que possui somente Protocolo de Licença; dois possuem arquivados os MTR (Manifesto de Transporte de Resíduos) como certificado pelo encaminhamento à destinação adequada dos resíduos gerados em suas instalaçóes; e, de acordo com os entrevistados, todos compartilham o PEI (Plano de Emergência Individual) do Porto Novo.

A manutenção de equipamentos, em três empresas, é realizada em oficinas mecânicas dentro de suas instalaçôes e nas demais não há locais apropriados para executar este serviço, o que não impede a sua realização. Como exceção, em uma das empresas, a manutenção dos equipamentos é terceirizado e efetuado externamente à área do Porto.

No Terminal Porto Novo não há movimentação de cargas perigosas, seguindo a categorização da Normatização da IMO - International Maritime Organization. De acordo com a caracterização realizada, a tipologia dos produtos movimentados neste Terminal envolve contêineres, automóveis, máquinas agrícolas, celulose e granéis, como soja, arroz, trigo e fertilizantes agrícolas. Estes últimos, embora sejam facilmente dispersos para o corpo hídrico, não são apontados como causa potencial de impactos ambientais de grandes proporções, pois os operadores deste terminal não são empresas de grande porte. Logo, o volume das mercadorias não é expressivamente alto, considerando individualmente cada um dos empreendimentos.

Partindo da realidade dos empreendimentos, que desenvolvem operaçóes de alto potencial poluidor, e considerando a hidrodinâmica do Estuário da Lagoa dos Patos, fator ambiental que interfere diretamente no ambiente do Terminal Porto Novo, os impactos ambientais potenciais 
das organizaçôes e empresas instaladas neste Terminal ultrapassam os limites territoriais de mais de um município, ou seja, o do Rio Grande e de São José do Norte. Logo, não podem ser considerados como impactos locais.

\section{A COMPETÊNCIA DO LICENCIAMENTO AMBIENTAL DOS OPERADORES PORTUÁRIOS}

As operaçôes portuárias se enquadram entre as atividades que necessitam de licenciamento ambiental, pois são atividades utilizadoras de recursos naturais, consideradas potencial e efetivamente poluidoras, estando em consenso com a legislação referida na Seção 3.

Há gestores que defendem o principio de que o licenciamento ambiental deve estar ligado sempre a uma instancia superior, ou seja, se a administração do porto for municipal, o licenciamento deve ser conduzido pelo órgão ambiental estadual; se for estadual, pelo órgão ambiental federal.

No caso do Porto Organizado do Rio Grande, a Licença de Operação do Porto é expedida pelo IBAMA, mas as licenças de operação dos terminais privativos é emitida pelo órgão estadual, FEPAM, e alguns operadores possuem sua licença expedida pelo órgão municipal, SMMA.

Alguns operadores portuários alegam que suas operaçóes, por serem exercidas no interior do Terminal Porto Novo, estariam cobertas pela Licença de Operação do Porto Organizado, mas tal alegação é inconcebível, uma vez que as condicionantes da LO 003/97 estabelece condicionantes de operação ao Porto como um todo e estas não são cumpridas pelos operadores.

As organizações que operam mercadorias no Porto do Rio Grande diferem entre si, assim como suas operaçóes e mercadorias movimentadas. Portanto, os aspectos e impactos ambientais de seus respectivos negócios igualmente diferem. Isso pressupóe que as operaçóes das empresas não devem ser incluídas na Licença de Operação do Porto Organizado do Rio Grande, pois com apenas uma licença, a análise do órgão federal seria extremamente genérica para aspectos e impactos distintos.

De acordo com Marroni et al. (2007), "a figura do município consolida-se como a melhor opção da viabilidade de implantação de um processo gerencial. Isso justifica-se, pois são os municípios que conseguem aglutinar melhor os esforços em prol do resgate da sustentabilidade local". São eles os que melhor conhecem a realidade da região, da comunidade e das organizaçóes. Apesar disso, em geral, o poder público municipal necessita de grande mobilização em relação à capacitação dos profissionais responsáveis pelo processo de emissão das licenças ambientais e fiscalização das atividades licenciadas.

Além disso, a competência sobre o licenciamento das operaçóes desenvolvidas em área federal e com alto potencial poluidor, como é o caso das atividades portuárias, deveriam ser atribuídas minimamente ao órgão ambiental estadual. Porém, cabe ressaltar a dificuldade de fiscalizar os empreendimentos locais por parte do órgão estadual, que não possui um escritório local em Rio Grande.

O fato é que os órgãos ambientais, sejam federais, estaduais ou municipais, não possuem um conhecimento claro e objetivo de como estão divididas as responsabilidades entre a Autoridade Portuária e os operadores portuários. Como afirma Kitzmann et al. (2006) "os diversos órgãos reguladores têm dificuldades para compatibilizar suas agendas de trabalho e integrar políticas e açóes, devido a visóes conflitantes do funcionamento do sistema portuário e das causas e soluçóes para os problemas ambientais ali gerados. Outro fator a ser destacado é a inconsistência das ações de regulação, que variam de porto a porto".

Para Asmus et al. (2004) "há uma grande quantidade de órgãos governamentais regulando a atividade portuária, distribuídos em vários ministérios, com funções não claramente definidas, gerando superposição de competências e enfoques não integrados de gestão. Há dificuldades em conciliar as agendas de trabalho e harmonizar as açóes, uma vez que os órgãos têm visóes diferentes do sistema portuário, de seu funcionamento e das causas e soluçóes para os problemas ambientais".

O licenciamento ambiental de atividades exercidas na área do Porto Organizado do Rio Grande deveria competir ao órgão ambiental federal, devido à sua área ser de domínio da Uniāo. Contudo, o IBAMA, na situação de órgão licenciador, delega o licenciamento das operaçóes portuárias nos terminais privados ao órgão estadual. Logo, o processo de licenciamento dos operadores instalados no interior do Terminal Porto Novo não deveria escapar muito destas circunstâncias, sendo ideal que órgão ambiental estadual (FEPAM) ou a SUPRG fossem os responsáveis pela emissão das licenças ambientais das empresas e companhias arrendatárias neste Terminal.

No entanto, delegar à Superintendência do Porto do Rio Grande a responsabilidade de licenciar as atividades dos operadores portuários poderia ser considerado um equívoco, partindo do princípio de que a SUPRG possui interesse na movimentação de mercadorias realizada pelos operadores.

Uma saída a essa problemática é o licenciamento único do Porto Organizado e a configuração da Autoridade Portuária como órgáo licenciador das atividades exercidas dentro de sua área. Outra proposta seria a do autolicenciamento, proposta que ganha força nas esferas federais, principalmente na Secretaria Especial de Portos.

A deficiência na fiscalização por parte da Autoridade Portuária corrobora com a atual realidade do Terminal Porto Novo de Rio Grande. A autoridade portuária, representada pela SUPRG, não cumpre adequadamente sua função de "fiscalizar as operaçóes portuárias, zelando para que os serviços se realizem com regularidade, eficiência, segurança e respeito ao meio ambiente" (Lei Federal 8.630/93) ao ignorar a apresentação de licenças ambientais por parte das empresas arrendatárias de suas instalaçóes.

\section{CONCLUSÃO}

O conjunto de discussóes apresentadas neste estudo demonstra os fatores que contribuem para a atual realidade do Terminal Porto Novo no que tange o licenciamento ambiental de seus operadores. O licenciamento ambiental autoriza os empreendedores a desenvolverem suas atividades e concomitantemente impóe medidas para atendimento das questóes ambientais. Como um instrumento de gestão, ele 
é exigido legalmente para empreendimentos utilizadores de recursos naturais considerados potencial ou efetivamente poluidores e, em razão disso, é nítida a necessidade de licença ambiental para operadores portuários.

Devido ao alto grau poluidor das atividades desenvolvidas e da singulares características da hidrodinâmica do Estuário da Lagoa dos Patos, os impactos ambientais gerados pelos operadores portuários do Terminal Porto Novo podem atingir dois municípios, Rio Grande e São José do Norte. Assim, de acordo com a legislação brasileira, a competência do licenciamento ambiental destes empreendimentos não deveria ser delegada ao órgão ambiental municipal. Ademais, o poder público municipal necessita de grande mobilização em relação à capacitação dos profissionais responsáveis pelo processo de emissáo das licenças ambientais e fiscalizaçáo das atividades licenciadas. Além disso, a competência sobre o licenciamento das operaçóes desenvolvidas em área federal e com alto potencial poluidor deveriam ser atribuídas minimamente ao órgão ambiental estadual.

As atividades dos operadores portuários, distante do que é entendido por estes atores, não estão cobertas pela Licença de Operação do Porto Organizado. No seu período de validade, que é de oito anos, as empresas que operam no Terminal podem ser alteradas, pois seus contratos independem desta licença ambiental. Além disso, as condicionantes desta LO não fazem menção alguma às atividades dos operadores portuários de nenhum dos terminais.

De acordo com a legislaçáo ambiental brasileira, o licenciamento ambiental de atividades exercidas na área do Porto Organizado do Rio Grande deveria competir ao órgão ambiental federal, devido à sua área ser de domínio da Uniâo. Contudo, o IBAMA delega o licenciamento das operaçôes portuárias nos terminais privados ao órgão estadual. Com base nesta premissa, o processo de licenciamento dos operadores instalados no interior do Terminal Porto Novo deveria manter esta linha, sendo o mais apropriado delegar esta responsabilidade ao órgão ambiental estadual.

A questão é que o conhecimento dos órgãos ambientais, sejam federais, estaduais ou municipais, ainda não estar claro sobre o limite que separa as responsabilidades entre as Autoridades Portuárias e os operadores portuários. Esta situação impede o atendimento pleno das questóes que lhes são atribuídas pelos órgãos ambientais em função das condicionantes das licenças.

Uma indicação ao atendimento desta problemática é o licenciamento único do Porto Organizado e a configuraçáo da Autoridade Portuária como órgão licenciador das atividades exercidas dentro de sua área. No entanto, delegar este encargo à Superintendência do Porto do Rio Grande poderia ser considerado um equívoco, devido ao fato da SUPRG possuir interesse na movimentação de mercadorias realizada pelos operadores.

Outra proposta pautável seria a do autolicenciamento, ideia bastante discutida e apoiada nas esferas federais, principalmente na Secretaria Especial de Portos, no que tange o licenciamento ambiental portuário no Brasil.

\section{REFERÊNCIAS BIBLIOGRÁFICAS}

ANTAQ (2011) - Porto Verde: Modelo Ambiental Portuário [Edição Atualizada]. 49p., ANTAQ - Agência Nacional de Transportes Aquaviários, Brasília, DF, Brasil. ISBN 978-8564964013. Disponível em: http://www.antaq. gov.br/Portal/pdf/PortoVerde.pdf

Asmus, M.L.; Kitzmann, D.I. (2004) - Gestão costeira no Brasil: estado atual e perspectivas. Versão Preliminar. s/p (62p.), Ecoplata - Programa de Apoyo a la Gestión Integrada en la Zona Costera Uruguaya, Montevideo, Uruguay. Disponível em http://www.ecoplata.org/wp-content/files_mf/ estudiosinopticogestioncosteraenbrasil.pdf

Barbieri, J.C. (2004) - Gestão ambiental empresarial: conceitos, modelos e instrumentos. 328p., Editora Saraiva, São Paulo, SP, Brasil. ISBN: 8502046616.

Bruyne, P.; Herman, J.; Schoutheete, M. (1977) - Dinâmica da pesquisa em ciências sociais. 84p., Editora Francisco Alves, Rio de Janeiro, RJ, Brasil.

Delaney, P.J.V. (1965) - Fisiografia e geologia da superfície da planície costeira do Rio Grande do Sul. 6:1-195, Publicação Especial da Escola de Geologia, Universidade Federal do Rio Grande do Sul, Porto Alegre, RS, Brasil.

Demore, J.P. (2001) - Aspectos sedimentares do Estuário da Lagoa dos Patos e sua interação com a poluição por petróleo: subsidios para um plano de contingência. 30p., Monografia de graduação, Oceanologia, Universidade Federal do Rio Grande, Rio Grande, RS, Brasil. Disponível em: http:// www.prh27.log.furg.br/site/wp-content/files_mf/130 6431619AspectossedimentaresdoestuariodaLagoados Patosesuainteracaocomapoluicaoporpetroleo_ subsidiosparaumplanodecontingencia.pdf

DHN. (1974) - Atlas de Cartas Piloto do Oceano Atlântico: Trindade ao Rio da Prata. 26p., Diretoria de Hidrografia e Navegação (DHN), Marinha do Brasil, Rio de Janeiro, RJ, Brasil.

DNPVN (1941) - Enchentes de maio de 1941. 61p., Relatório Técnico, Diretoria Nacional de Portos e Vias de Navegação (DNPVN), Porto Alegre, RS, Brasil. Não publicado.

Herz, R. (1977) - Circulaçâo das águas de superfície da Lagoa dos Patos. 722p., Tese de Doutorado, Faculdade de Filosofia Letras e Ciências Humanas. Departamento de Geografia, Universidade de São Paulo, São Paulo, SP, Brasil. Não publicado.

Kitzmann, D.I.S.; Asmus, M. (2006) - Gestão ambiental portuária: Desafios e possibilidades. Revista de Administração Pública (RAP), (ISSN: 0034-7612), 40(6):1049-1060, Fundação Getúlio Vargas, Rio de Janeiro-RJ Brasil. Disponível em hhttp://www.scielo.br/ pdf/rap/v40n6/06.pdf

Marroni, E.V.; Asmus, M.L. (2005) - Gerenciamento Costeiro. Uma proposta para o fortalecimento comunitário na gestão ambiental. 149p., Uniâo SulAmericana de Estudos da Biodiversidade, Pelotas, RS, Brasil. ISBN: 8589985067.

Möller, O.O.; Paim, P.S.G.; Soares, I.D. (1991) - Effects and mechanisms of water circulation in the Patos Lagoon Estuary. Bulletin Institute Géologique, 49:15-21, Paris, France. 
Seeliger, U.; Odebrecht C.; Castello J.P. (Eds.) (1998) - Os ecossistemas costeiro e marinho do extremo sul do Brasil. 341p., Editora Ecoscientia, Rio Grande, RS, Brasil. ISBN: 8587167014. Disponível em: http://www2. furg.br/instituto/io/ecoveco/ecomidia/livros/Os $\% 20$ Ecossistemas\%20Costeiro\%20e\%20Marinho\%20 do\%20Extremo\%20Sul\%20do\%20Brasil.pdf

\section{LEGISLAÇÁO}

Lei Federal no 6.938, de 31 de agosto de 1981. Dispóe sobre a Política Nacional do Meio Ambiente, seus fins e mecanismos de formulação e aplicação, e dá outras providências. Publicado no D.O.U. de 2.9.1981, Brasília, DF, Brasil. Disponível em: http://www.planalto.gov.br/ ccivil_03/leis/16938.htm

Lei Federal 8.630, de 25 de fevereiro de 1993. Dispóe sobre o regime jurídico da exploração dos portos organizados e das instalaçôes portuárias e dá outras providências. (Lei dos Portos) [Revogado pela Lei $n^{\circ} 12.815$, de 2013]. Publicado no D.O.U. de 26.2.1993, Brasília, DF, Brasil. Disponível em: http://www.planalto.gov.br/ccivil_03/ leis/18630.htm
Lei Estadual 11.520, de 03 de agosto de 2000. Institui o Código Estadual de Meio Ambiente do Estado do Rio Grande do Sul e dá outras providências. Porto Alegre, RS, Brasil. Disponível em: http://www.mp.rs.gov.br/ ambiente/legislacao/id628.htm

Lei Municipal 6.365, de 21 de março de 2007. Dispóe sobre o licenciamento ambiental e as sanções administrativas pelo seu descumprimento no município do Rio Grande e dá outras providências. Rio Grande, RS, Brasil. Disponível em: http://www.riogrande.rs.gov.br/pagina/arquivos/lei/ lei_6.365_-_licenciamento_ambiental.pdf

Resolução CONAMA 237, de 19 de novembro de 1993. Dispóe sobre os procedimentos e critérios utilizados no Licenciamento Ambiental. Conselho Nacional do Meio Ambiente (CONAMA), Brasília, DF, Brasil. Disponível em: http://www. mma.gov.br/port/conama/res/res97/res23797.html

Resolução CONDEMA 001, de janeiro de 2011. Dispóe sobre o Licenciamento Ambiental Municipal das atividades de preponderante interesse local. Conselho Municipal de Defesa do Meio Ambiente (CONDEMA), Rio Grande, RS, Brasil.Disponívelem:http://www.riogrande.rs.gov.br/ pagina/arquivos/arquivo/4d63a4ea72fa8Resolucao\%20 COMDEMA.pdf 